\title{
CONF-9308143--5
}

\section{A Smart Control System For Electric Vehicle Batteries}

\author{
Muralidharan P. Arikara, Blake E. Dickinson, Brian Branum \\ Texas Engineering Experiment Station \\ Texas A\&M University System
}

\section{Abstract}

A smart control system for electric vehicle (EV) batteries was designed and its performance was evaluated. The hardware for the system was based on the Motorola

MC68HC11ENB micro controller. A zinc bromide $\left(\mathrm{Zn} / \mathrm{Br}_{2}\right)$ battery was choosen since it is a good candidate as an EV battery and has a large number of user variable parameters that affect its performance.

The flexibility of the system arises from the fact that the system can be programmed to do a wide variety of jobs. The use of real time interrupts and other features makes the system safe for use along with the battey systems.

Test data indicates that real time control of the different parameters can increase the performance of the battery by $15 \%$. In addition to optimizing the performance of the battery the control system incorporates essential safety features.

\section{Introduction}

The enactment of the legislation in California requiring a mix of various levels of low and zero emission vehicles in each manufacturers fleet beginning 1998 has posed a challenge for automobile manufacturers. It is apparent that such vehicles would be vying against the time tested fossil fuel powered automobiles. It is necessary to optimize the performance of the entire system to help in providing a suitable alternative to the conventional fossil fuel powered automobiles. Any limitations on the performance of the electric vehicles as a whole arises out of limitations of the battery. A suitable control system which will optimize the performance of the battery will improve the overall vehicle performance.

This paper presents the design for one such control system. The control system is based around the MC68HCIIENB micro controller from Motorola. In addition to the microprocessor there are other electronic interface circuits to provide the link between the microprocessor and the battery system. The system is flexible since it can be used with any battery technology. In this paper we discuss the use of this control system with the Zinc

\section{MASTER}


Bromide battery system $(\mathrm{Zn} / \mathrm{Br} 2)$. The battery system was chosen to demonstrate the operational capabilities of the system since it has a large number of user variable parameters which could affect the performance of the battery.

An electric vehicle should be easy to operate from the view point of the customer. A smart controller which can decide the parameters of the battery for optimum performance will do such a job.

\section{Zinc Bromide Technology:}

The battery is constructed from mostly plastic parts and is modular in design. The basic components are two electrolyte reservoirs and an electrode stack. The electrolyte is an aqueous Zinc/Bromide solution with organic complexers. The complexers bond with the bromine for safety because gaseous bromine is poisonous. The complexer is constantly bonding and releasing bromine so that a supply of bromide ions is available for the battery. Pumps circulate the electrolyte through the electrode stack. On charging, metallic zinc is deposited on the anodes while bromine evolves at the cathode. The bromine is complexed and is stored in the catholyte reservoir. On discharge the electrolytic process is reversed. A valve is used to control the percentage of complexed bromine in the electrolyte during the operation of the battery. The complexer is a poor conductor so too much complexed bromine increases the internal resistance of the battery. However, sufficient bromine is needed to power the battery so the flow of complexed bromine needs to be maintained between two extremes. A simple flow diagram for the battery system is shown in figure 1.(1)

\section{DISCLAIMER}

This report was prepared as an account of work sponsored by an agency of the United States Government. Neither the United States Government nor any agency thereof, nor any of their employees, makes any warranty, express or implied, or assumes any legal liability or responsibility for the accuracy, completeness, or usefulness of any information, apparatus, product, or process disclosed, or represents that its use would not infringe privately owned rights. Reference herein to any specific commercial product, process, or service by trade name, trademark, manufacturer, or otherwise does not necessarily constitute or imply its endorsement, recommendation, or favoring by the United States Government or any agency thereof. The views and opinions of authors expressed herein do not necessarily state or reflect those of the United States Government or any agency thereof. 


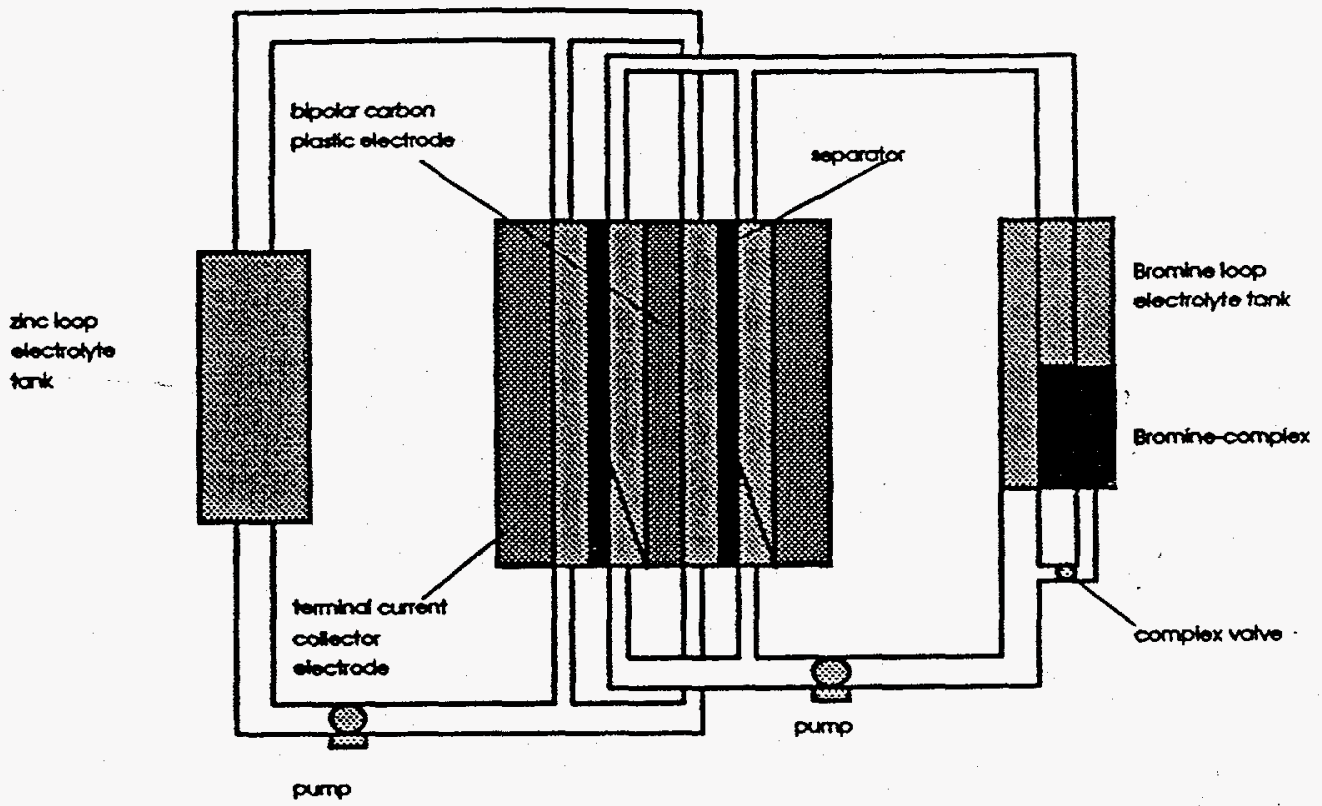

Figure 1. Schematic of the Zinc Bromide battery system with main components

Design parameters of the controller

Safety and Reliability

Temperature: The temperature of the battery must be maintained below $45^{\circ} \mathrm{C}$ to ensure that the bromine remains complexed.

Electrolyte Leakage: The electrolyte must be contained within the battery for the following reasons:

(a) Free bromine is a health hazard.

(b) The electrolyte is very corrosive to metals.

(c) $\mathrm{Zn} / \mathrm{Br}_{2}$ is highly conductive and can short circuit the battery system.

(d) The electrolyte is expensive.

Current. The current should be limited to a maximum of $200 \mathrm{~mA} / \mathrm{cm}^{2}$ to control the temperature of the electrolyte. In this battery, the electrode area is $1000 \mathrm{~cm}^{2}$ so a maximum of 200 amps is allowed per stack.

Battery Strip: After a maximum of 10 charge discharge cycles the battery must be short circuited at the end of discharge with the pumps running for 8 to 12 hours. This strips the zinc buildup off of the anode. An optional method to decrease stripping time is available and will be tried if time permits. This method would consist of controlling two four way valves to chemically strip the anode.

Standby: This battery cannot be turned off arbitrarily. If it is not in use, the pump continues moving the 
electrolyte but the complexer valve is shut off so no bromine is added.

Shutdown: To turn off the battery, the circuit is opened and the battery goes into a standby mode. It then must be discharged through a resistor until most of the bromine in the stack is used up and, finally, the pump can be turned off.
Pump Speed: The rate of flow of electrolyte will be varied depending upon the state of charge and rate of discharge of the battery.

Complex Valve Position: The complex valve position will be controlled to ensure the ideal amount of bromine is available to the electrode.

\section{Performance:}

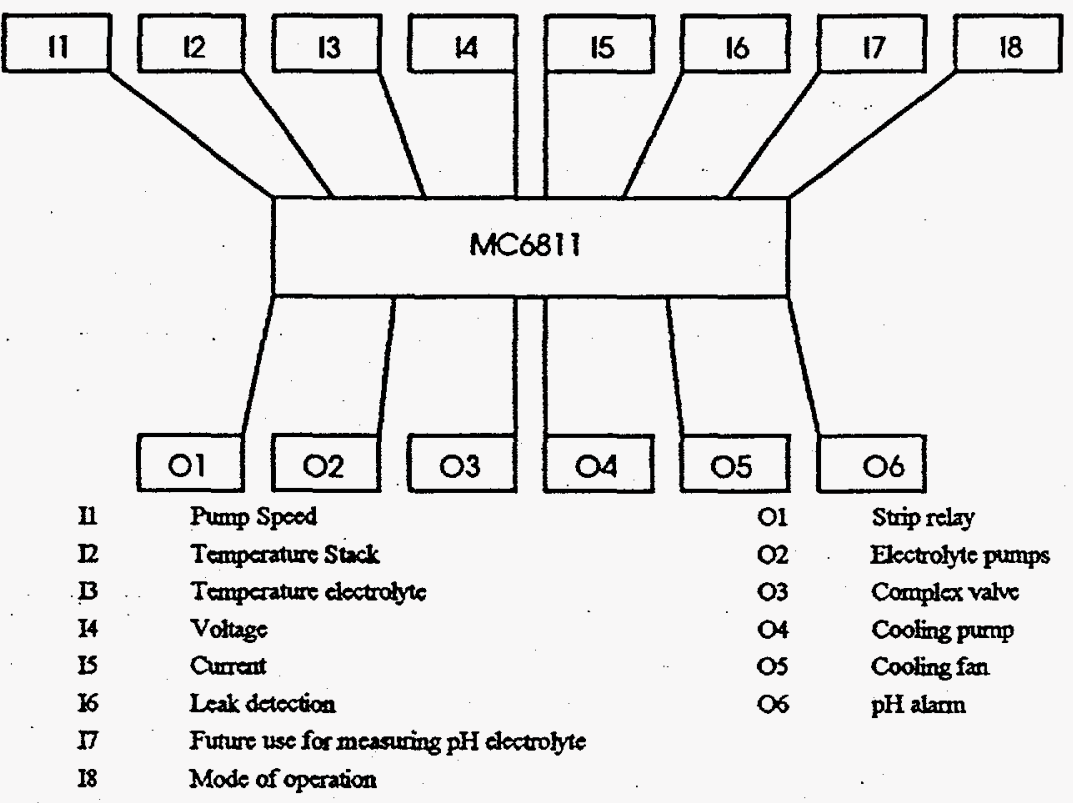

Figure 2. Schematic of Inputs and Outputs of the Microprocessor 


\section{System design}

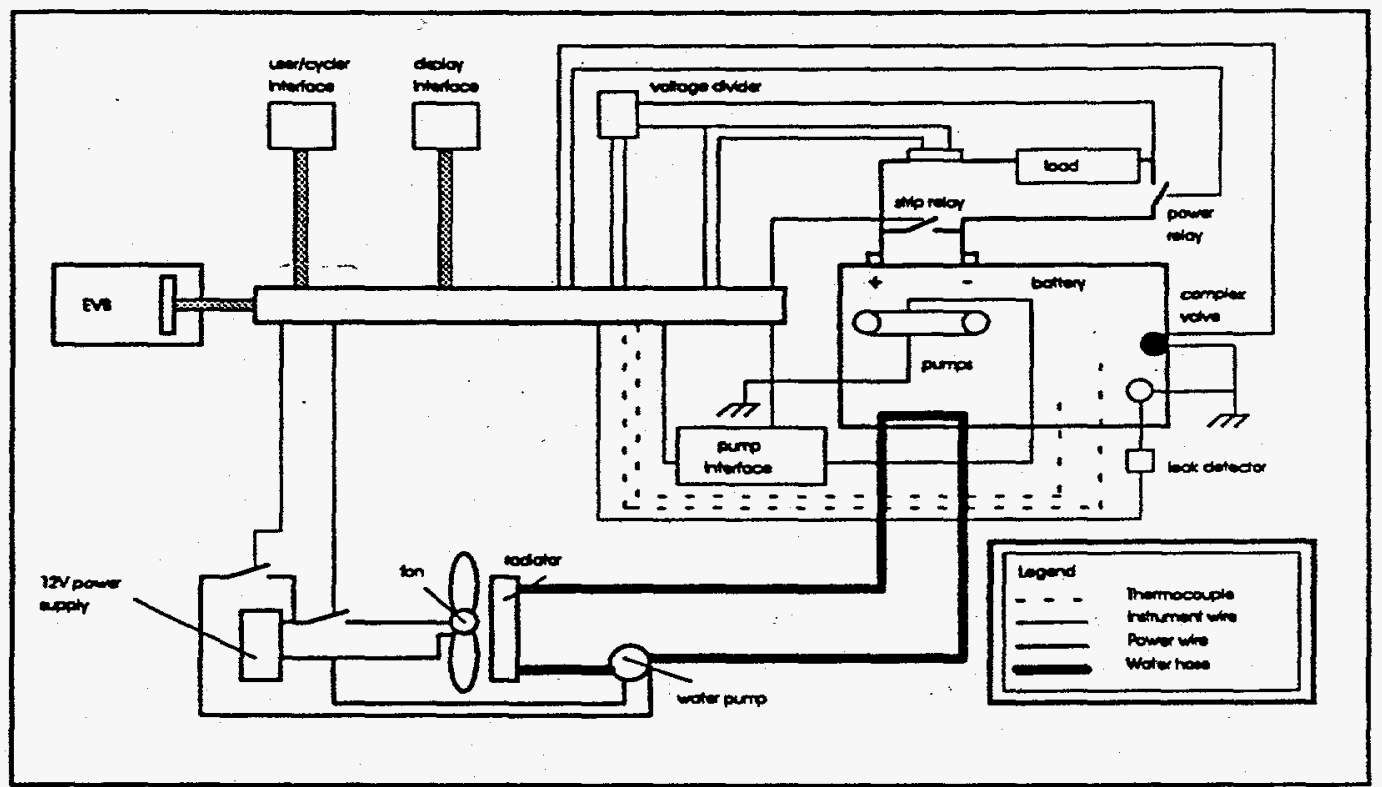

Figure 3. Schematic of the control sytem and battery interface

Figure 2 shows the various input and output parameters of the system. Based on these values the system control would be executed. Figure 3 gives the schematic of the control system and battery interface. The system design shows the different equipment used of the system. The EVB or the Motorola microprocessor board is connected to each of the units either directly or through interfaces. The interfaces are used since the microprocessor and the external device power requirements are not of the same order.

In case of emergencies the control system is capable of running a safety routine the moment the condition is detected whatever it may have been doing prior to the occurrence of the condition. A lot of interface devices are used to ensure proper communication between the controller and the battery system. The capabilities of the control system are indicated in the section below.

\section{Controller design capabilities}

The controller will do the following.

- If the battery electrolyte temperature is above $45^{\circ} \mathrm{C}$, the battery will enter standby mode. 
- If a leak is detected the pumps are immediately stopped, the load is removed and an alarm is activated.

- If the current is above $200 \mathrm{~mA} / \mathrm{cm}^{2}$ then an alarm is activated. If current is above $400 \mathrm{~mA} / \mathrm{cm}^{2}$ the load is removed.

- A counter sums up the number of complete charge discharge cycles and when the number of cycles equals ten the controller puts the battery in the strip mode, a manual override is provided for the strip. At this time, it is not clear if the battery should perform the strip automatically because it could mean downtime for the battery at a nonoptimal time.

- The electrolyte pump speed control will be based on state of charge of the battery; open loop control is sufficient for this task.

- The complex valve position will be based on concentration of bromine in the electrolyte.

The flexibility of the controller helps it in working with the motor controller units and coordinating the activity of the motor controller unit. Thus the system can be made the brain of the entire vehicle. The design looks into making the system failsafe. In the event of failure of the controller the system would proceed to the shutdown mode. The system is being built and will be implemented in two to three weeks time where it will be tested in the laboratory to show the improvement in performance. A $5 \mathrm{kwh}$ Zinc Bromide battery was used to test the performance of the system. The main design considerations have already been specified in the previous sections. The system was built on a prototype board which was neatly laid out. The system can be divided into two main sections.

- Inputs to the MC68HCll

- Outputs from the $\mathrm{MC} 68 \mathrm{HCl} 1$ The inputs to the system are:

1. Voltage of the battery. (analog)

2. Current drawn by the battery. (analog)

3. Temperature of the electrolyte. (analog)

4. Temperature of the surrounding air. (analog)

5. Mode of operation. (digital) The outputs from the system are:

1. Signals to the relays. (digital)

2. Digital output to the D/A for the servo valve control. (analog)

3. Emergency alarm signals lighting up LEDs and sounding the beeper. (digital)

4. PWM control signal for the electrolyte pumps. (digital)

Voltage, Current and temperature of the system were read into the system using the $A / D$ channel provided on the 
EVB. The reference values for the A/D converter were taken directly from the supply. Reference low was $\mathrm{OV}$ and reference high was $5 \mathrm{~V}$. Different interface circuits had to be used to read these parameters from the battery system into the EVB. The basic problem was that the range of the measurements for the different inputs varied from a few millivolts to about a hundred volts. It was necessary to condition the parameters for the interface so that the hardware could be appropriately interfaced to the EVB.

Figure 4. shows the signal amplifier circuit used with the temperature measurements. The values of the reading from the thermocouples was of the order of a few millivolts. This value was appropriately scaled by using a gain of about 700 to read values in the range from $0-5 \mathrm{~V}$.

The current going into and out of the battery was measured using a shunt resistance such that $\operatorname{lmV}$ represented 1 Amp. This signal is amplified by a factor of 12.5 using an op amp. To read both negative and positive values of the current we have to add a simple adder circuit using op amps since the A/D does not allow a negative reference value. An adder circuit was used to add five volts and divide by two before being read by the A/D converter. The battery voltage was reduced by a factor of 13 (i.e. if the bridge outputted IV it would mean the battery voltage was truly $13 \mathrm{~V}$ ). The mode of operation of the battery was fed into the system using switched logic. The mode of operation was read from port $A$ of the microcontroller using pins $\mathrm{PA} 0$ to PA2. The user could choose the mode by flipping switches. In real operation, the signals would come from user friendly inputs like an ignition. Table 1 shows the logic used for mode selection.

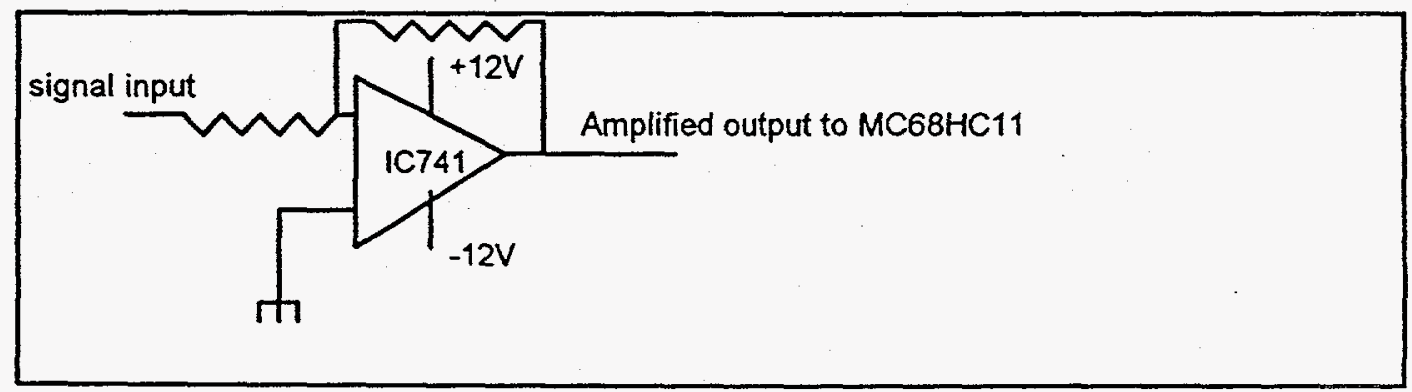

Figure 4. Signal amplifier circuit 
Table 1 Logic for the different operating modes.

\begin{tabular}{|c|c|}
\hline Logic & Mode \\
\hline 000 & Washout \\
\hline 001 & Charge \\
\hline 010 & Discharge \\
\hline 011 & Strip \\
\hline 100 & Error \\
\hline 101 & Extended \\
\hline 110 & Error \\
\hline 111 & Error \\
\hline
\end{tabular}

All the relays available for switching on and off the different modes required a $12 \mathrm{~V}$ signal to operate. Since the EVB could not put out voltages of that magnitude, smaller relays were used to operate on a $5 \mathrm{~V}$ activation signal, these relays activated the 12 volt relays.
Digital output was supplied to the $D / A$ converter for operating the servo valve by using pins $\mathrm{PC} 0$ to $\mathrm{PC} 3$ of port $\mathrm{C}$ of the microcontroller board. The circuit diagram of the connections to the $\mathrm{D} / \mathrm{A}$ converter are shown in figure 5 .

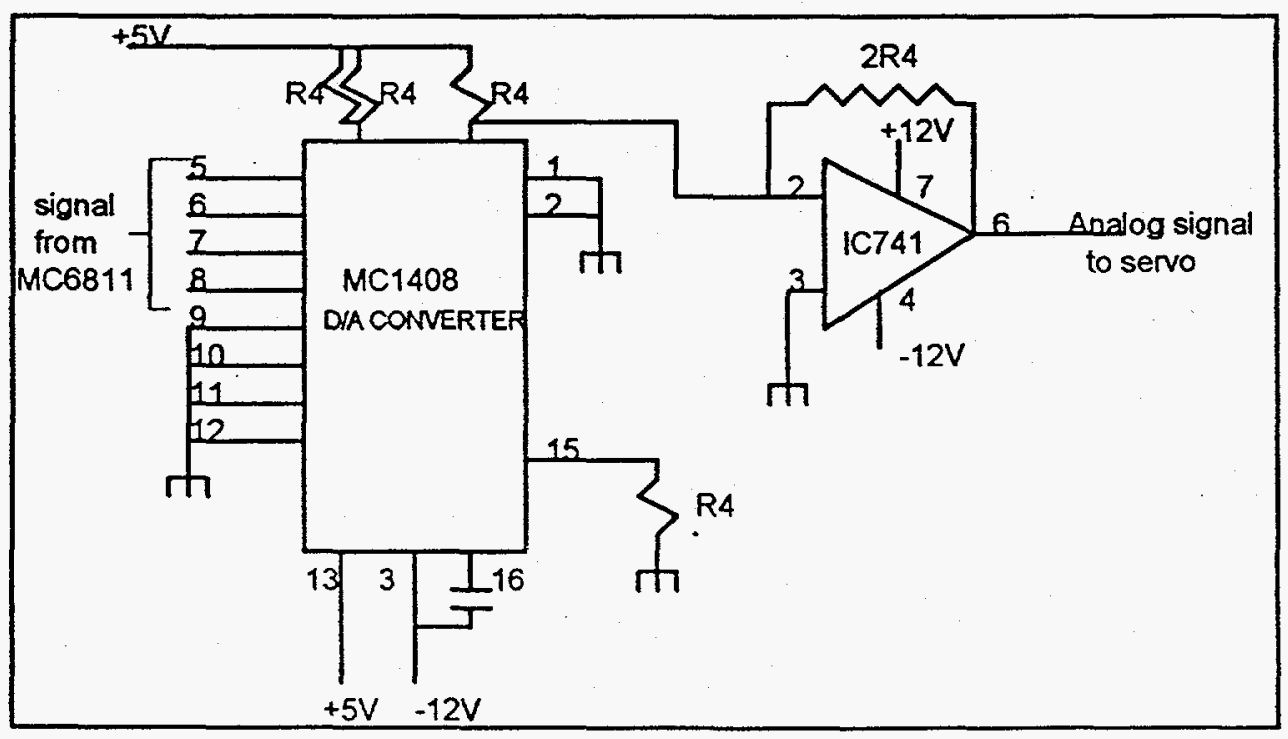


Figure 5. D/A converter circuit for the Servo

The value of the output voltage varied from $0 \mathrm{~V}$ to $2 \mathrm{~V}$ which corresponds to fully closed or fully opened respectively.

The pulse width modulated control for the electrolyte pumps would make sure that the speed of the pumps remain at the required value based on the rate of discharge of the battery. The only problem was that while the pumps needed $30 \mathrm{~V}$ for operating at full speed the board could output only a maximum of 5V. An interface using a MOSFET whose gate signal was the pulse from the board was built. The MOSFET acted like a switch and would turn on and off the $30 \mathrm{~V}$ supply to the pump to follow the pulse from the board.

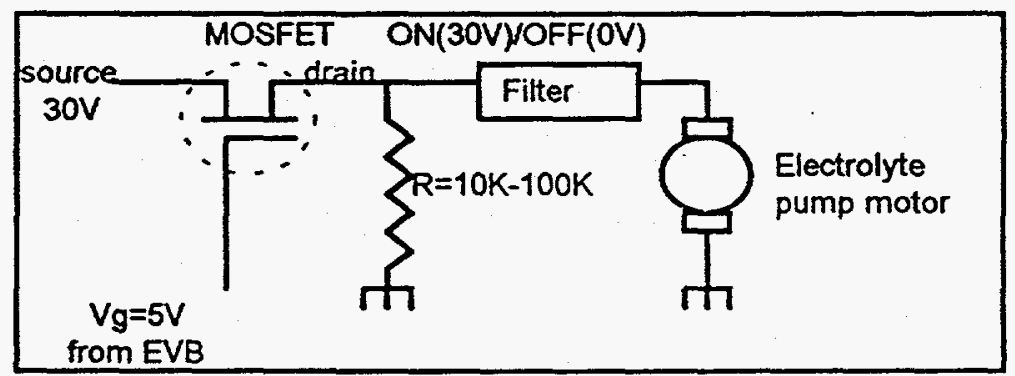

Figure 6. Pump Interface Circuit

\section{SOFTWARE LOGIC}

The goal of the software is to maintain the battery in a safe and efficient operating mode. In general, this is accomplished by first waming the operator that a parameter (i.e. temperature) is approaching an emergency state and then shutting down the system if it becomes dangerous.

It, basically, puts the microcontroller into one of nine modes. Based on the mode and the measured values, it determines the state of the relays, controls pump speed, and controls complex valve position. Both the pump speed and the valve position are controlled open loop because it is sufficient and reduces the complexity of the system. The pump speed is controlled with a PWM signal from the microcontroller. The servo valve uses a 4 bit D/A converter on pins using one of the ports of the microcontroller (port C).

The different modes of the controller are interrupt driven, this allows the processor to know what the user wants, but not allow it if there is a safety constraint. Reading the inputs using interrupts, makes it easier to override the operators desires for safety reasons. 
Finally, the timer is used to keep track of how long the battery has been in a certain mode. For example, the battery should be stripped for a certain amount of time and then charged. The processor uses the timer to switch modes when necessary.

\section{Conclusions}

A smart way of controlling batteries and providing them with optimum operating conditions which would make the battery powered electric vehicle an easy to drive and highly efficient mode of transportation. The flexibility which arises in this system as a result of the programmability makes it easy to adjust to different battery technologies. Fuel cells which also need complex controls can be controlled by this system by adjusting a few parameters.

\section{References}

(1) The Zinc-Bromine battery development by SEA, G.S.Tomazic, SEA, Austria, 11 th international electric vehicle symposium, Florence (1992). 